\title{
An Analysis of Influencing Factors in Collaboration of the Three Industries in Sichuan Province, China
}

\author{
Zhigang Liu \\ Postdoctoral, Associate professor, Institue of Economics \\ School of Humanities \& Social Sciences, Tsinghua University, Beijing 100084, China \\ Guanghui Zhu \\ Associate Professor, Deputy Dean, School of Liberal Art \\ Beijing Institute of Technology, Beijing 100081, China \\ Caibin Zhu \\ Lecturer, School of Economics, Beijing Wuzi University, Beijing 101149, China
}

Received: October 29, 2012

Accepted: November 3, $2012 \quad$ Online Published: November 12, 2012

doi:10.5430/ijba.v3n6p113

URL: http://dx.doi.org/10.5430/ijba.v3n6p113

\begin{abstract}
In the past few years, the Chinese government has promulgated in succession seven strategic emerging industries development plans, ten industrial development plans, Chengdu-Chongqing economic zone planning and the outline of the $12^{\text {th }}$ five-year plan. The country has attached more and more importance on the mode of industrial development, the direction of development and path of development. The industries should not be developed rapidly, but should also be developed with health and collaboration. Industrial collaboration is a self requirement of industrial development in the future and is also a long-term target.

This article studies the collaborative development condition of the three industries in Sichuan Province under the above background. Through an analysis on the establishment of indicator system for evaluation on collaboration of the three industries, it is discovered that there are still a lot of problems that are urgent to be adjusted and improved in collaborative development of the three industries in Sichuan Province. Through the Principal Component Analysis, we find out the principal influencing factors for collaborative development of the three industries in Sichuan Province, which includes the three major influencing factors of relevant industries in construction and real estate, tourism industry and great industrial industry. Given the existing problems at present in collaboration of the three industries in Sichuan Province, this article proposes the five policy suggestions of accelerating adjustment of industrial structure, making full use of resource endowment to develop regional economy, boost healthy and orderly development of construction and real estate industry, encouraging rapid development of tourism industry, bringing in steady development of new types of strategic industries and carrying forward industrial transfer and supporting industrial cluster. The aim of these five policy suggestions is to promote collaborative development of the three industries in Sichuan Province, resolve the issue of $1+1>2$ and $1+1+1>3$, better facilitate industrial promotion in Sichuan Province and lay a foundation and provide conditions for fast and benign development of industries in Sichuan Province.
\end{abstract}

Keywords: Collaboration of the three industries, Factor analysis, Indicator system, Principal component analysis

\section{Introduction}

In the past few years, with rapid development of the national economy, the pace of adjustment of economic structure and optimization and upgrading becomes faster and when the country pursues economic development speed, it also attaches more importance to economic structure and economic development efficiency. The country has promulgated several development plans to develop the new types of strategic industries. Economic development plans in relevant function supporting regions are also being prepared and following up closely. As a national plan to develop Sichuan and Chongqing, Chengdu-Chongqing economic zone planning also emerges accordingly under such a background. 
However, analysis of the current industrial structure and industrial collaboration in Sichuan Province is the basis and support for follow-up economic development. Study on the status quo of collaborative development of the three industries in Sichuan Province not only has theoretical significance, but also has realistic significance, and the study has materialized and quantified abstract collaboration and realized integration of multiple disciplines. At the same time, the study also has certain realistic significance in that it has well connected Chengdu-Chongqing economic zone planning and has offered reference for development and implementation of Chengdu-Chongqing economic zone planning. The study in this article helps to find out the primary influencing factors in collaboration of the three industries in Sichuan Province and offer a framework for other provinces to study the issue of collaboration of the three industries.

\section{Literature Review}

Scholars at home and abroad all have been involved in industrial collaboration. Among the foreign academics, the German Physicist Herman Haken was the first who concentrated on industrial collaboration. Haken (1971-1983) published successively "Introduction to Synergetics" and "Advanced Synergetics" with his students and initiated the pioneering work in study on industrial collaboration. Afterwards, study on synergetics became gradually a key research topic by more and more foreign academics. Chinese domestic scholars also have dedicated great enthusiasm in study on industrial collaboration. Among the existing studies, there are some that begin from the perspective of change of industrial structure. Among all the studies, the study by Liu Wei and Li Shaorong (2002) is relatively of great influence who mainly analyze the important role of the tertiary industry in collaboration of three industries. In addition, there are studies from the perspective of industrial organization (yang Jirui, 2003), from the perspective of industrial chain (Gong Qinlin, 2004) and from the perspective of regional space (An Husen, 2005) et al. Domestic scholars have achieved certain achievements in their studies on industrial collaboration. Nonetheless, a general survey at the current studies on collaboration of the three industries, it is found that there have been relatively a large number of qualitative studies and relatively a small number of quantitative studies. This article mainly employs the factor analysis method and principal component analysis to analyze existing problems and influencing factors in collaboration of the three industries in Sichuan province and enrich current studies on industrial collaboration. This has provided more research perspectives and methods for study of industrial collaboration.

\section{Establishment of Indicator System and Source of Data}

\subsection{Principles to Establish Indicator System}

Establishment of indicator system should follow the following five principles to make the indicators established more pertinent and more persuasive.

\subsubsection{Principle of Comprehensiveness}

We ought to select as many as indicators in establishment of the system of evaluation indicators in the hope of attempting to avoid loss of data and enabling any useful indicators to be brought in the indicator system.

\subsubsection{Principle of Comparability}

Most data about indicators come from different regions. Due to difference in the population base, economic indicators in different regions may differ greatly from each other. Therefore, it is necessary to calculate more frequently on the ratio of these economic indicators with the expectation of achieving comparability of indicators.

\subsubsection{Principle of Objectivity}

Selection of data is supposed to be more objective and with more operability, so as to try to reduce difficulties in collecting, sorting out and using the data.

\subsubsection{Principle of Representativeness}

There might be a lot of indicators for measuring collaboration of the three industries. However, in actual establishment of indicator system, it is out of the question to exhaust all indicators. Thus, selection of indicators has to be representative and can well measure and reflect the condition of collaborative development of the three industries.

\subsubsection{Principle of Gradation}

Under the goal of collaboration of the three industries, we further subdivide the overall indicator of economic development, indicator of collaboration between the three industries and indicator of collaboration within each of the three industries, so as to be distinct and clear. 


\subsection{Selection of Indicators}

In this system, in order to better make evaluation on collaboration of the three industries, this article mainly establishes the indictor system from the five aspects of total economic aggregate indicator, indicator of collaboration within the primary industry, indicator of collaboration within the secondary industry, indicator of collaboration within the tertiary industry and indicator of collaboration between the three industries.

$<$ Insert Table 1 Here $>$

\section{Analysis of Collaboration of the Three Industries and the Result}

\subsection{Analysis Method}

Evaluation on collaboration of the three industries mainly adopts the method of factor analysis method. With the factor analysis method, this article gives a mark on collaboration of the three industries and gets the integrate score of factors in collaboration of the three industries according to the weight of factors. At the same time, the article gets the score of a single item with the factor analysis method. Based on the scores, we can find out the ranking of collaborative development of the three industries in Sichuan Province. Yet, considering the score of a single item, we can also discover differences of all autonomous prefectures in the process of industrial development.

\subsection{Analysis Procedure}

(1) Collecting and sorting out data about the second class indicators

(2) Nondimensionalization processing of data

(3) Calculating the integrate Score

\subsection{Analysis Result of Collaboration of the Three Industries}

(1) Collecting of Data

Collecting of data employed in this article mainly refers to the "Sichuan Statistical Yearbook in 2010" and statistical bulletin of all autonomous prefectures in Sichuan Province in 2009. In order to obtain relevant indicators, we might process and total up relevant data.

(2) Modeling

According to the principal component analysis and all known conditions, we set up the following model:

$$
X=A F+a_{i j} \varepsilon
$$

Where, $X=\left(X_{1} \ldots X_{P}\right)$ stands for $P$ original variables, and $F$ stands for $m$ public factor variables, $m \leq P ; A$ stands for the factor loading matrix of $P \times m ; a_{i j}$ stands for the correlation coefficient of the $i_{\text {th }}$

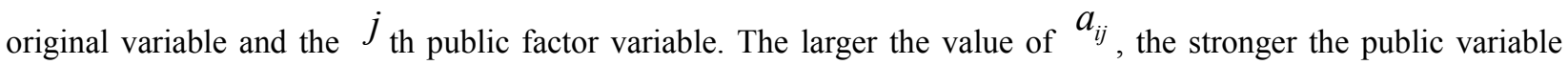

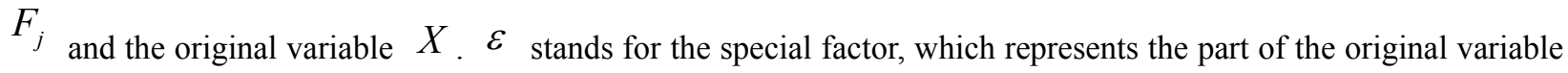
that can't be explained by the public factor variable and which equals to the residual part in the multiple regression analysis (Note 1).

Calculating through SPSS, we get the total variance explained:

$<$ Insert Table 2 Here>

We take the variance contribution of the principal factor as the weight and substitute it into the model:

$$
Y=61.594 \% F_{1}+14.446 \% F_{2}+7.547 \% F_{3}+4.259 \% F_{4}+3.587 \% F_{5}
$$

Then, we substitute the score of factors into the model and get the integrate score of factors, as is shown in the following Table: 
$<$ Insert Table 3 Here $>$

\subsection{Summary of Problems Existing in Collaboration of the Three Industries in Sichuan Province}

(1) Considering the integrate score, the integrate score of factors in Chengdu, Deyang, Mianyang, Yibin, Leshan and Nanchong has a high ranking, whereas the integrate score of the three autonomous prefectures of Ngawa Tibetan and Qiang Autonomous Prefecture, Bazhong and Kardze Tibetan Autonomous Prefecture has a low ranking.

(2) Considering the total economic aggregate, from the scores of a single factor, we can find that the overall economic strength in Chengdu, Mianyang, Deyang \& Nanchong is powerful, whereas the total local economic aggregate in such national minorities as Ngawa Tibetan and Qiang Autonomous Prefecture and Kardze Tibetan Autonomous Prefecture is relatively fragile.

(3) Considering collaboration within the primary industry, good work has been done in Nanchong and Ziyang, whereas Zigong, Ya'an and Panzhihua are still open for further improvement.

(4) Considering collaboration within the second industry, Panzhihua and Deyang are developed in a more collaborative way, whereas Bazhong, Ngawa Tibetan and Qiang Autonomous Prefecture and Kardze Tibetan Autonomous Prefecture have a relatively worse situation.

(5) Considering collaboration within the tertiary industry, the tertiary industry in Chengdu and Zigong has taken the leading role, whereas development speed in Panzhihua and Meishan is relatively slow.

\section{An Analysis of Influencing Factors in Collaborative Development of the Three Industries in Sichuan Province}

There exist quite a lot of problems in collaborative development of the three industries in Sichuan Province, with low degree of collaboration and obvious regional differences. What are the reasons for existence of these problems and what are the influencing factors? These are major issues to be resolved in this article. Through the indicator system that has been established in Section 4 and by applying the principal component analysis and analysis of relevant factors, we find out the major factors that affect collaboration of the three industries in Sichuan Province and provide evidence on this basis for proposing policies and suggestions in the next section.

\subsection{Employment of Analysis Method}

There are various categories for analysis methods of influencing factors, such as, econometrics model method, grey correlation analysis method and fuzzy mathematical analysis. The econometrics model method consumes degree of freedom and has great difficulty in collecting and sorting data, while the calculation process of grey correlation analysis method is also complicated. The fuzzy mathematical analysis method is suitable for fuzzy analysis and is mainly used for simple, qualitative and abstract analysis. By contrast, the principal component analysis is easy to handle, able to make an analysis of multiple indicators and extract major influencing factors and propose policies and suggestions according to principal factors.

\subsection{Principal Component Analysis and Correlation Analysis of Influencing Factors}

The data mainly come from the statistical bulletin and statistical yearbook of all cities and autonomous prefectures in Sichuan Province in 2009 and some data have been processed accordingly.

\subsection{Result of Principal Component Analysis and Analysis of Reasons}

\subsubsection{Result of Principal Component Analysis}

We employ SPSS analysis software to make the principal component analysis and correlation analysis and get the following result.

\section{$<$ Insert Table 4 Here $>$}

From the above table, it can be seen that both in the case of initial variance contribution and in the case of rotated variance contribution, the cumulative variance contribution rate of the three factors all achieves $83.587 \%$, which can almost explain a large majority of influencing factors. The eigenvalue of the first factor is 18.423 , with a variance contribution rate of $55.827 \%$; the eigenvalue of the second factor is 6.172 , with a variance contribution rate of $18.703 \%$; the eigenvalue of the third factor is 2.989 , with a variance contribution rate of $9.057 \%$. Hence, we can extract the three principal factors to analyze problems in collaboration of the three industries in Sichuan Province.

$<$ Insert Table 5 Here $>$

The first factor mainly explains these fifteen variables, which represents the relevant industries of construction and real estate or upstream and downstream industries in construction and real estate. This factor has great influences on 
collaboration of the three industries and is the principal influencing factor in collaboration of the three industries in Sichuan Province.

The second factor mainly explains these twelve variables, which represents the tourism industry. The effect of tourism industry on collaborative interaction of the three industries can not be underestimated.

The third factor mainly explains these six variables, which represents large-scale industries or industries that are closely connected with the industry.

\subsubsection{Analysis of Reasons}

The reason why relevant industries of construction and real estate are the major influencing factors for collaboration of the three industries in Sichuan Province is listed as follows:

(1) Construction and real estate is the major income source for local financial revenue.

(2) There are a great number of upstream and downstream industries that are correlated with construction and real estate industry which have great influences.

(3) The publicity effect of tourism industry is obvious in that it can stimulate regional investment.

(4) The industrial chain of upstream and downstream industries of tourism is long and has great ability to drive development of relevant industries.

(5) The category covered by industry is extensive and has a long industrial chain.

(6) Industrial development is in a transition period and re-positioning of industrial development will bring more influences on collaborative development of the three industries in the future.

\section{Policies and Suggestions}

\subsection{To Speed up Adjustment of Industrial Structure and Make Full Use of Resource Endowment to Develop Regional Economy}

We ought to make full use of differences of resource endowment in all regions of Sichuan Province and alternatively develop labor intensive industries, capital intensive industries and technology intensive industries in some regions. We may take advantages of local resource endowment with the help of relevant preferential policies, attract more investors and entrepreneurs to focus on and participate in regional economic development, strengthen confidence and cohesive force of regional economic development, accelerate economic development, improve the overall level of industrial collaboration and better promote collaboration of the three industries in Sichuan Province.

\subsection{To Boost Healthy and Orderly Development of Construction and Real Estate Industry}

We need to do a good job in the following four aspects in order to standardize development of construction and real estate industry and guarantee healthy and orderly development of real estate industry.

Firstly, it is necessary to clarify the development chaos of construction and real estate industry at present.

Secondly, it is necessary to diminish dependence of local government on land revenue.

Thirdly, it is necessary to carry out a plan ahead of schedule for development of construction and real estate industry.

Fourthly, it is necessary to make a plan about usage and approval of funds in construction and real estate industry.

\subsection{To Encourage Rapid Development of Tourism Industry}

We need to do a good job in the following three aspects to encourage development of tourism industry.

Firstly, we need to attach importance to development of tourism industry and enhance the influencing power of tourism industry.

Secondly, we need to improve supporting measures for development of tourism industry and improve the service level of tourism.

Thirdly, we need to expand the coverage scope of tourism industry and develop more tourism projects.

\subsection{To Bring in New Types of Strategic Industries for Steady Development}

The new types of strategic industries have important strategic position in collaborative development of the three industries at a high level. Thus, we need to do a good job in the following two aspects.

On one hand, it is important to attach great importance to the historical position of the new types of strategic industries and recognize the importance of developing new types of strategic industries. 
On the other hand, it is important for Sichuan Province to promulgate relevant policies and measures to guarantee development of new types of strategic industries.

\section{References}

An, Husen. (2005). An Introduction to Regional Economics. Economic Science Press.

Dong, Chun, \& Da, Jie. (2008). Study on Collaborative Development of the Three Industries in Sichuan Province. Reform of the Economic System, (6), 35-38.

Gong, Qinlin. (2004). On construction of industrial chain and urban and rural coordinating development. The Economist World, (3).

Hu, Lijun, Shi, Junwei, \& et al. (2005). On Implemental Mechanism of Inter-action between Industrial Structure and Industrial Organization. China Industrial Economics, (5).

Liu, Ninging. (2009). Analysis of Connotation and Mechanism of Regional Industrial Linkage. Theory Front, (6).

Liu, Wei, \& Li, Shaorong. (2002). Industrial Structure and Economic Growth. China Industrial Economics, (5).

Liu, Wei. (1996). Study on Industrial Structure during the Industrialization. China Renmin University Press.

Marx. (1975). Capital, Volume 2. People's Publishing House.

Wang, Jici. (2001). Innovative Spaces: Enterprise Clusters and Regional Development. Peking University Press.

William, G. Shepherd, \& Joanna, M.Shpherd. (2003). Economics of Industrial Organization. China Renmin University Press.

Yang, Jirui. (2003). On the Strategic Thinking for "the Mutual-operation of the Three Industries and Integration of Urban and Rural Economy". Rural Economy, (2).

Zhu, Shun. (2001). General Theory of County Economics --- Study on China Administrative Regional Economy. People's Publishing House.

\section{Note}

Note 1. Yan, Gang, Xiong, Na \& Zhu, Xubin. (2008). Performance Assessment of China's Leading Listed Agricultural Companies by Factor Analysis. Journal of Jiangxi Agricultural University (Social Sciences Edition), (9). 
Table 1. Indicator system for evaluation on collaborative development of the three industries in Sichuan Province




Table 2. Variance contribution

\begin{tabular}{|c|c|c|c|c|c|c|}
\hline \multirow[b]{2}{*}{ Component } & \multicolumn{3}{|c|}{ Extraction Sums of Squared Loadings } & \multicolumn{3}{|c|}{ Rotation Sums of Squared Loadings } \\
\hline & Total & $\begin{array}{c}\% \text { of } \\
\text { Variance }\end{array}$ & $\begin{array}{c}\text { Cumulative } \\
\% \\
\end{array}$ & Total & $\begin{array}{c}\% \text { of } \\
\text { Variance }\end{array}$ & $\begin{array}{c}\text { Cumulative } \\
\% \\
\end{array}$ \\
\hline 1 & 20.326 & 61.594 & 61.594 & 18.759 & 56.845 & 56.845 \\
\hline 2 & 4.767 & 14.446 & 76.040 & 5.265 & 15.953 & 72.798 \\
\hline 3 & 2.490 & 7.547 & 83.587 & 2.220 & 6.727 & 79.525 \\
\hline 4 & 1.405 & 4.259 & 87.845 & 2.017 & 6.113 & 85.637 \\
\hline 5 & 1.184 & 3.587 & 91.432 & 1.912 & 5.795 & 91.432 \\
\hline
\end{tabular}

Extraction Method: Principal Component Analysis.

Table 3. Integrate score of factors in all regions in Sichuan Province and the ranking of the score

\begin{tabular}{lrr}
\hline Name of place & Integrate score & Ranking of integrate score \\
\hline Chengdu & 2.673384 & 1 \\
Deyang & 0.278951 & 2 \\
Mianyang & 0.272916 & 3 \\
Yibin & 0.204804 & 4 \\
Leshan & 0.069118 & 5 \\
Nanchong & 0.012098 & 6 \\
Dazhou & -0.02474 & 7 \\
Luzhou & -0.05361 & 8 \\
Ziyang & -0.06098 & 9 \\
Meishan & -0.06538 & 10 \\
Neijiang & -0.09523 & 11 \\
Zigong & -0.09882 & 12 \\
Panzhihua & -0.13728 & 13 \\
Liangshan Yi Autonomous Prefecture & -0.15457 & 14 \\
Guang'an & -0.16405 & 15 \\
Suining & -0.18892 & 16 \\
Ya'an & -0.27477 & 17 \\
Guangyuan & -0.28639 & 18 \\
Ngawa Tibetan and Qiang Autonomous & & 19 \\
Prefecture & -0.34082 & 20 \\
Bazhong & -0.35414 & 21 \\
Kardze Tibetan Autonomous Prefecture & -0.46142 & \\
\hline & & \\
\hline
\end{tabular}


Table 4. Total variance explained

\begin{tabular}{|c|c|c|c|c|c|c|c|c|c|}
\hline \multirow{2}{*}{$\begin{array}{c}\text { Com } \\
\text { pone } \\
\text { nt }\end{array}$} & \multicolumn{3}{|c|}{ Initial Eigenvalues } & \multicolumn{3}{|c|}{$\begin{array}{l}\text { Extraction Sums of } \\
\text { Squared Loadings }\end{array}$} & \multicolumn{3}{|c|}{$\begin{array}{c}\text { Rotation Sums of Squared } \\
\text { Loadings }\end{array}$} \\
\hline & Total & $\begin{array}{c}\% \text { of } \\
\text { Variance }\end{array}$ & $\begin{array}{l}\text { Cumulati } \\
\text { ve } \%\end{array}$ & Total & $\begin{array}{c}\% \text { of } \\
\text { Varian } \\
\text { ce }\end{array}$ & $\begin{array}{c}\text { Cumul } \\
\text { ative } \\
\%\end{array}$ & Total & $\begin{array}{c}\% \text { of } \\
\text { Varian } \\
\text { ce }\end{array}$ & $\begin{array}{c}\text { Cumul } \\
\text { ative } \\
\%\end{array}$ \\
\hline 1 & 20.326 & 61.594 & 61.594 & 20.326 & 61.594 & 61.594 & 18.423 & 55.827 & 55.827 \\
\hline 2 & 4.767 & 14.446 & 76.040 & 4.767 & 14.446 & 76.040 & 6.172 & 18.703 & 74.530 \\
\hline 3 & 2.490 & 7.547 & 83.587 & 2.490 & 7.547 & 83.587 & 2.989 & 9.057 & 83.587 \\
\hline 4 & 1.405 & 4.259 & 87.845 & & & & & & \\
\hline 5 & 1.184 & 3.587 & 91.432 & & & & & & \\
\hline 6 & .786 & 2.382 & 93.814 & & & & & & \\
\hline 7 & .629 & 1.907 & 95.721 & & & & & & \\
\hline 8 & .328 & .993 & 96.714 & & & & & & \\
\hline 9 & .299 & .907 & 97.620 & & & & & & \\
\hline 10 & .207 & .626 & 98.247 & & & & & & \\
\hline 11 & .151 & .457 & 98.703 & & & & & & \\
\hline 12 & .118 & .357 & 99.060 & & & & & & \\
\hline 13 & .104 & .314 & 99.374 & & & & & & \\
\hline 14 & .092 & .280 & 99.654 & & & & & & \\
\hline 15 & .050 & .151 & 99.805 & & & & & & \\
\hline 16 & .033 & .100 & 99.905 & & & & & & \\
\hline 17 & .018 & .053 & 99.958 & & & & & & \\
\hline 18 & .007 & .020 & 99.978 & & & & & & \\
\hline 19 & .004 & .013 & 99.991 & & & & & & \\
\hline 20 & .003 & .009 & 100.000 & & & & & & \\
\hline 21 & $8.46 \mathrm{E}-016$ & $2.56 \mathrm{E}-015$ & 100.000 & & & & & & \\
\hline 22 & $5.84 \mathrm{E}-016$ & $1.77 \mathrm{E}-015$ & 100.000 & & & & & & \\
\hline 23 & 4.78E-016 & $1.45 \mathrm{E}-015$ & 100.000 & & & & & & \\
\hline 24 & $3.60 \mathrm{E}-016$ & $1.09 \mathrm{E}-015$ & 100.000 & & & & & & \\
\hline 25 & $1.29 \mathrm{E}-016$ & $3.90 \mathrm{E}-016$ & 100.000 & & & & & & \\
\hline 26 & $\begin{array}{c}-5.67 \mathrm{E}-01 \\
7\end{array}$ & $\begin{array}{c}-1.72 \mathrm{E}-01 \\
6\end{array}$ & 100.000 & & & & & & \\
\hline 27 & $\begin{array}{c}-1.73 \mathrm{E}-01 \\
6\end{array}$ & $\begin{array}{c}-5.25 \mathrm{E}-01 \\
6\end{array}$ & 100.000 & & & & & & \\
\hline 28 & $\begin{array}{c}-2.50 \mathrm{E}-01 \\
6\end{array}$ & $\begin{array}{c}-7.58 \mathrm{E}-01 \\
6\end{array}$ & 100.000 & & & & & & \\
\hline 29 & $\begin{array}{c}-4.14 \mathrm{E}-01 \\
6\end{array}$ & $\begin{array}{c}-1.25 \mathrm{E}-01 \\
5\end{array}$ & 100.000 & & & & & & \\
\hline 30 & $\begin{array}{c}-5.39 \mathrm{E}-01 \\
6\end{array}$ & $\begin{array}{c}-1.63 \mathrm{E}-01 \\
5\end{array}$ & 100.000 & & & & & & \\
\hline 31 & $\begin{array}{c}-6.97 \mathrm{E}-01 \\
6\end{array}$ & $\begin{array}{c}-2.11 \mathrm{E}-01 \\
5\end{array}$ & 100.000 & & & & & & \\
\hline 32 & $\begin{array}{c}-8.72 \mathrm{E}-01 \\
6\end{array}$ & $\begin{array}{c}-2.64 \mathrm{E}-01 \\
5\end{array}$ & 100.000 & & & & & & \\
\hline 33 & $\begin{array}{c}-1.62 \mathrm{E}-01 \\
5\end{array}$ & $\begin{array}{c}-4.92 \mathrm{E}-01 \\
5 \\
\end{array}$ & 100.000 & & & & & & \\
\hline
\end{tabular}

Extraction Method: Principal Component Analysis. 
Table 5. Rotated component matrix(a)

\begin{tabular}{|c|c|c|c|}
\hline & \multicolumn{3}{|c|}{ Component } \\
\hline & 1 & 2 & 3 \\
\hline GDP & .973 & .223 & -.004 \\
\hline Investment amount of fixed capital & .968 & .164 & .113 \\
\hline Local financial revenue & .958 & .232 & .119 \\
\hline Rural per capita annual net income & .538 & .658 & -.444 \\
\hline Urban per capita disposable income & .519 & .674 & .244 \\
\hline Local Financial Expenditure & .978 & .110 & .067 \\
\hline Output value of the primary industry & -.119 & .788 & -.479 \\
\hline Ratio of plantation & .295 & .574 & -.203 \\
\hline Ratio of animal husbandry \& fishery & -.163 & -.590 & -.145 \\
\hline Ratio of agricultural service & .011 & .671 & .140 \\
\hline $\begin{array}{c}\text { Appreciation of town and township } \\
\text { enterprise }\end{array}$ & .920 & .309 & -.146 \\
\hline Total power of agricultural machinery & .413 & .113 & .807 \\
\hline rural power consumption & .136 & .276 & .888 \\
\hline Output value of the secondary industry & .947 & .312 & -.014 \\
\hline Industrial value added & -.047 & .367 & .921 \\
\hline $\begin{array}{l}\text { Total output value of construction } \\
\text { industry }\end{array}$ & .966 & .190 & .097 \\
\hline Investment of real estate & .965 & .174 & .134 \\
\hline Amount of sales in commodity housing & .967 & .172 & .134 \\
\hline Finance and insurance & .970 & .195 & .108 \\
\hline $\begin{array}{l}\text { Traffic Transportation, warehousing and } \\
\text { posts and telecommunications }\end{array}$ & .932 & .276 & -.041 \\
\hline $\begin{array}{l}\text { Total appropriation expenditure of } \\
\text { scientific and technological activities }\end{array}$ & .025 & .269 & .888 \\
\hline Income of tourism & .228 & .939 & .172 \\
\hline Income of hotels and catering & .206 & .976 & .014 \\
\hline Income of wholesale and retail & .178 & .981 & .028 \\
\hline Ratio of the primary industry & -.285 & -.890 & -.227 \\
\hline Ratio of the secondary industry & -.128 & .935 & -.174 \\
\hline Ratio of the tertiary industry & .629 & -.284 & .624 \\
\hline $\begin{array}{l}\text { Contribution ratio of the primary industry } \\
\text { to GDP }\end{array}$ & -.019 & .039 & -.335 \\
\hline $\begin{array}{l}\text { Contribution ratio of the secondary } \\
\text { industry to GDP }\end{array}$ & -.012 & .681 & -.465 \\
\hline $\begin{array}{l}\text { Contribution ratio of the tertiary industry } \\
\text { to GDP }\end{array}$ & .789 & -.391 & 0.080 \\
\hline $\begin{array}{l}\text { Ratio of employment of the primary } \\
\text { industry }\end{array}$ & .166 & -.718 & -0.457 \\
\hline $\begin{array}{c}\text { Ratio of employment of the secondary } \\
\text { industry }\end{array}$ & .258 & 0.379 & .655 \\
\hline $\begin{array}{c}\text { Ratio of employment of the tertiary } \\
\text { industry }\end{array}$ & .606 & .542 & .251 \\
\hline
\end{tabular}

Extraction Method: Principal Component Analysis.

Rotation Method: Varimax with Kaiser Normalization.

a. Rotation converged in 6 iterations. 